\title{
Educação e a
}

Apropriação e

Reconstrução do

\section{Conhecimento}

\section{Científico}

Américo Junior Nunes da Silva Ilvanete dos Santos de Souza Reinaldo Feio Lima (Organizadores)
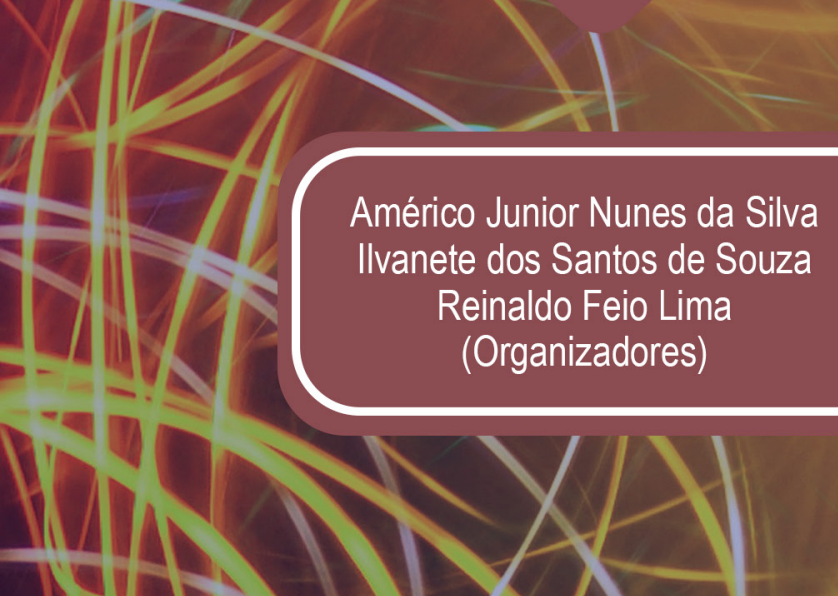


\section{Educação e a}

Apropriação e

Reconstrução do

\section{Conhecimento}


Editora Chefe

Prof $^{a}$ Dr $^{\mathrm{a}}$ Antonella Carvalho de Oliveira

Assistentes Editoriais

Natalia Oliveira

Bruno Oliveira

Flávia Roberta Barão

Bibliotecária

Janaina Ramos

Projeto Gráfico e Diagramação

Natália Sandrini de Azevedo

Camila Alves de Cremo

Luiza Alves Batista

Maria Alice Pinheiro

Imagens da Capa

Shutterstock

Edição de Arte

Luiza Alves Batista

Revisão

Os Autores
2020 by Atena Editora

Copyright (c) Atena Editora

Copyright do Texto (c) 2020 Os autores

Copyright da Edição (c) 2020 Atena Editora

Direitos para esta edição cedidos à Atena

Editora pelos autores.

Todo o conteúdo deste livro está licenciado sob uma Licença de Atribuição Creative Commons. Atribuição-Não-ComercialNãoDerivativos 4.0 Internacional (CC BY-NC-ND 4.0).

O conteúdo dos artigos e seus dados em sua forma, correção e confiabilidade são de responsabilidade exclusiva dos autores, inclusive não representam necessariamente a posição oficial da Atena Editora. Permitido o download da obra e o compartilhamento desde que sejam atribuídos créditos aos autores, mas sem a possibilidade de alterá-la de nenhuma forma ou utilizá-la para fins comerciais.

Todos os manuscritos foram previamente submetidos à avaliação cega pelos pares, membros do Conselho Editorial desta Editora, tendo sido aprovados para a publicação.

A Atena Editora é comprometida em garantir a integridade editorial em todas as etapas do processo de publicação. Situações suspeitas de má conduta científica serão investigadas sob o mais alto padrão de rigor acadêmico e ético.

\section{Conselho Editorial}

Ciências Humanas e Sociais Aplicadas

Prof. Dr. Alexandre Jose Schumacher - Instituto Federal de Educação, Ciência e Tecnologia do Paraná

Prof. Dr. Américo Junior Nunes da Silva - Universidade do Estado da Bahia

Prof. Dr. Antonio Carlos Frasson - Universidade Tecnológica Federal do Paraná

Prof. Dr. Antonio Gasparetto Júnior - Instituto Federal do Sudeste de Minas Gerais

Prof. Dr. Antonio Isidro-Filho - Universidade de Brasília

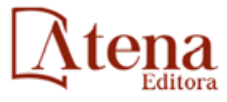


Prof. Dr. Carlos Antonio de Souza Moraes - Universidade Federal Fluminense

Prof $^{a}$ Dr $^{\text {a }}$ Cristina Gaio - Universidade de Lisboa

Prof. Dr. Daniel Richard Sant'Ana - Universidade de Brasília

Prof. Dr. Deyvison de Lima Oliveira - Universidade Federal de Rondônia

Prof $^{\mathrm{a}}$ Dr $^{\mathrm{a}}$ Dilma Antunes Silva - Universidade Federal de São Paulo

Prof. Dr. Edvaldo Antunes de Farias - Universidade Estácio de Sá

Prof. Dr. Elson Ferreira Costa - Universidade do Estado do Pará

Prof. Dr. Eloi Martins Senhora - Universidade Federal de Roraima

Prof. Dr. Gustavo Henrique Cepolini Ferreira - Universidade Estadual de Montes Claros

Prof $^{a} \mathrm{Dr}^{\mathrm{a}}$ Ivone Goulart Lopes - Istituto Internazionele delle Figlie de Maria Ausiliatrice

Prof. Dr. Jadson Correia de Oliveira - Universidade Católica do Salvador

Prof. Dr. Julio Candido de Meirelles Junior - Universidade Federal Fluminense

Prof $^{\mathrm{a}} \mathrm{Dr}^{\mathrm{a}}$ Lina Maria Gonçalves - Universidade Federal do Tocantins

Prof. Dr. Luis Ricardo Fernandes da Costa - Universidade Estadual de Montes Claros

Prof $^{a}$ Dr $^{a}$ Natiéli Piovesan - Instituto Federal do Rio Grande do Norte

Prof. Dr. Marcelo Pereira da Silva - Pontifícia Universidade Católica de Campinas

Prof $^{a}$ Dr $^{a}$ Maria Luzia da Silva Santana - Universidade Federal de Mato Grosso do Sul

Prof ${ }^{a}$ Dr $^{a}$ Paola Andressa Scortegagna - Universidade Estadual de Ponta Grossa

Prof $^{a}$ Dr $^{a}$ Rita de Cássia da Silva Oliveira - Universidade Estadual de Ponta Grossa

Prof. Dr. Rui Maia Diamantino - Universidade Salvador

Prof. Dr. Urandi João Rodrigues Junior - Universidade Federal do Oeste do Pará

Prof $^{a}$ Dr $^{a}$ Vanessa Bordin Viera - Universidade Federal de Campina Grande

Prof. Dr. William Cleber Domingues Silva - Universidade Federal Rural do Rio de Janeiro

Prof. Dr. Willian Douglas Guilherme - Universidade Federal do Tocantins

\section{Ciências Agrárias e Multidisciplinar}

Prof. Dr. Alexandre Igor Azevedo Pereira - Instituto Federal Goiano

Prof $^{a}$ Dr $^{a}$ Carla Cristina Bauermann Brasil - Universidade Federal de Santa Maria

Prof. Dr. Antonio Pasqualetto - Pontifícia Universidade Católica de Goiás

Prof. Dr. Cleberton Correia Santos - Universidade Federal da Grande Dourados

Prof $^{a}$ Dr $^{\mathrm{a}}$ Daiane Garabeli Trojan - Universidade Norte do Paraná

Prof ${ }^{a}$ Dr $^{a}$ Diocléa Almeida Seabra Silva - Universidade Federal Rural da Amazônia

Prof. Dr. Écio Souza Diniz - Universidade Federal de Viçosa

Prof. Dr. Fábio Steiner - Universidade Estadual de Mato Grosso do Sul

Prof. Dr. Fágner Cavalcante Patrocínio dos Santos - Universidade Federal do Ceará

Prof ${ }^{a}$ Dr $^{a}$ Girlene Santos de Souza - Universidade Federal do Recôncavo da Bahia

Prof. Dr. Jael Soares Batista - Universidade Federal Rural do Semi-Árido

Prof. Dr. Júlio César Ribeiro - Universidade Federal Rural do Rio de Janeiro

Prof $^{a}$ Dr $^{a}$ Lina Raquel Santos Araújo - Universidade Estadual do Ceará

Prof. Dr. Pedro Manuel Villa - Universidade Federal de Viçosa

Prof $^{\mathrm{a}}$ Dr $^{\mathrm{a}}$ Raissa Rachel Salustriano da Silva Matos - Universidade Federal do Maranhão

Prof. Dr. Ronilson Freitas de Souza - Universidade do Estado do Pará

Prof $^{a}$ Dr $^{a}$ Talita de Santos Matos - Universidade Federal Rural do Rio de Janeiro

Prof. Dr. Tiago da Silva Teófilo - Universidade Federal Rural do Semi-Árido

Prof. Dr. Valdemar Antonio Paffaro Junior - Universidade Federal de Alfenas

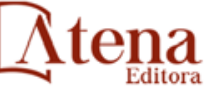

Ano 2020 


\section{Ciências Biológicas e da Saúde}

Prof. Dr. André Ribeiro da Silva - Universidade de Brasília

Prof $^{a}$ Dr $^{a}$ Anelise Levay Murari - Universidade Federal de Pelotas

Prof. Dr. Benedito Rodrigues da Silva Neto - Universidade Federal de Goiás

Prof $^{\mathrm{a}} \mathrm{Dr}^{\mathrm{a}}$ Débora Luana Ribeiro Pessoa - Universidade Federal do Maranhão

Prof. Dr. Douglas Siqueira de Almeida Chaves -Universidade Federal Rural do Rio de Janeiro

Prof. Dr. Edson da Silva - Universidade Federal dos Vales do Jequitinhonha e Mucuri

Prof $^{a}$ Dr $^{a}$ Eleuza Rodrigues Machado - Faculdade Anhanguera de Brasília

Prof $^{a}$ Dr $^{a}$ Elane Schwinden Prudêncio - Universidade Federal de Santa Catarina

Prof $^{\mathrm{a}} \mathrm{Dr}^{\mathrm{a}}$ Eysler Gonçalves Maia Brasil - Universidade da Integração Internacional da Lusofonia Afro-Brasileira

Prof. Dr. Ferlando Lima Santos - Universidade Federal do Recôncavo da Bahia

Prof $^{a}$ Dr $^{a}$ Gabriela Vieira do Amaral - Universidade de Vassouras

Prof. Dr. Gianfábio Pimentel Franco - Universidade Federal de Santa Maria

Prof. Dr. Helio Franklin Rodrigues de Almeida - Universidade Federal de Rondônia

Prof $^{a}$ Dr $^{a}$ lara Lúcia Tescarollo - Universidade São Francisco

Prof. Dr. Igor Luiz Vieira de Lima Santos - Universidade Federal de Campina Grande

Prof. Dr. Jefferson Thiago Souza - Universidade Estadual do Ceará

Prof. Dr. Jesus Rodrigues Lemos - Universidade Federal do Piauí

Prof. Dr. Jônatas de França Barros - Universidade Federal do Rio Grande do Norte

Prof. Dr. José Max Barbosa de Oliveira Junior - Universidade Federal do Oeste do Pará

Prof. Dr. Luís Paulo Souza e Souza - Universidade Federal do Amazonas

Prof $^{a}$ Dr $^{a}$ Magnólia de Araújo Campos - Universidade Federal de Campina Grande

Prof. Dr. Marcus Fernando da Silva Praxedes - Universidade Federal do Recôncavo da Bahia

Prof ${ }^{a} \operatorname{Dr}^{a}$ Maria Tatiane Gonçalves Sá - Universidade do Estado do Pará

Prof $^{a}$ Dr $^{a}$ Mylena Andréa Oliveira Torres - Universidade Ceuma

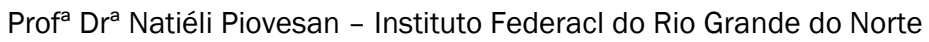

Prof. Dr. Paulo Inada - Universidade Estadual de Maringá

Prof. Dr. Rafael Henrique Silva - Hospital Universitário da Universidade Federal da Grande Dourados

Prof ${ }^{a}$ Dr $^{a}$ Regiane Luz Carvalho - Centro Universitário das Faculdades Associadas de Ensino

Prof $^{a}$ Dr $^{a}$ Renata Mendes de Freitas - Universidade Federal de Juiz de Fora

Prof $^{a}$ Dr $^{\text {a }}$ Vanessa Lima Gonçalves - Universidade Estadual de Ponta Grossa

Prof $^{a}$ Dr $^{\mathrm{a}}$ Vanessa Bordin Viera - Universidade Federal de Campina Grande

\section{Ciências Exatas e da Terra e Engenharias}

Prof. Dr. Adélio Alcino Sampaio Castro Machado - Universidade do Porto

Prof. Dr. Carlos Eduardo Sanches de Andrade - Universidade Federal de Goiás

Prof ${ }^{a}$ Dr $^{a}$ Carmen Lúcia Voigt - Universidade Norte do Paraná

Prof. Dr. Douglas Gonçalves da Silva - Universidade Estadual do Sudoeste da Bahia

Prof. Dr. Eloi Rufato Junior - Universidade Tecnológica Federal do Paraná

Prof $^{a}$ Dr $^{a}$ Érica de Melo Azevedo - Instituto Federal do Rio de Janeiro

Prof. Dr. Fabrício Menezes Ramos - Instituto Federal do Pará

Prof $^{a}$ Dra. Jéssica Verger Nardeli - Universidade Estadual Paulista Júlio de Mesquita Filho

Prof. Dr. Juliano Carlo Rufino de Freitas - Universidade Federal de Campina Grande

Prof $^{\mathrm{a}} \mathrm{Dr}^{\mathrm{a}}$ Luciana do Nascimento Mendes - Instituto Federal de Educação, Ciência e Tecnologia

do Rio Grande do Norte

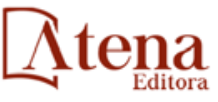

Ano 2020 
Prof. Dr. Marcelo Marques - Universidade Estadual de Maringá

Prof $^{a} D^{a}{ }^{a}$ Neiva Maria de Almeida - Universidade Federal da Paraíba

Prof $^{a}$ Dra $^{a}$ Natiéli Piovesan - Instituto Federal do Rio Grande do Norte

Prof ${ }^{a}$ Dr $^{a}$ Priscila Tessmer Scaglioni - Universidade Federal de Pelotas

Prof. Dr. Takeshy Tachizawa - Faculdade de Campo Limpo Paulista

\section{Linguística, Letras e Artes}

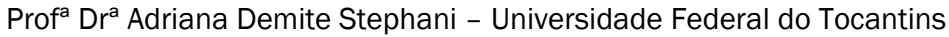

Prof $^{\mathrm{a}} \mathrm{Dr}^{\mathrm{a}}$ Angeli Rose do Nascimento - Universidade Federal do Estado do Rio de Janeiro

Prof $^{a}$ Dr $^{a}$ Carolina Fernandes da Silva Mandaji - Universidade Tecnológica Federal do Paraná

Prof $^{a}$ Dr $^{a}$ Denise Rocha - Universidade Federal do Ceará

Prof. Dr. Fabiano Tadeu Grazioli - Universidade Regional Integrada do Alto Uruguai e das Missões

Prof. Dr. Gilmei Fleck - Universidade Estadual do Oeste do Paraná

Prof $^{a}$ Dr $^{a}$ Keyla Christina Almeida Portela - Instituto Federal de Educação, Ciência e Tecnologia do Paraná

Prof $^{a}$ Dr $^{a}$ Miranilde Oliveira Neves - Instituto de Educação, Ciência e Tecnologia do Pará

Prof $^{a}$ Dr $^{a}$ Sandra Regina Gardacho Pietrobon - Universidade Estadual do Centro-Oeste

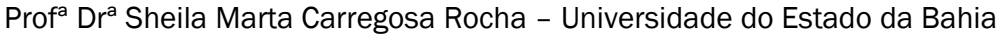

\section{Conselho Técnico Científico}

Prof. Me. Abrãao Carvalho Nogueira - Universidade Federal do Espírito Santo

Prof. Me. Adalberto Zorzo - Centro Estadual de Educação Tecnológica Paula Souza

Prof. Me. Adalto Moreira Braz - Universidade Federal de Goiás

Prof. Dr. Adaylson Wagner Sousa de Vasconcelos - Ordem dos Advogados do Brasil/Seccional Paraíba

Prof. Dr. Adilson Tadeu Basquerote Silva - Universidade para o Desenvolvimento do Alto Vale do Itajaí

Prof. Me. Alexsandro Teixeira Ribeiro - Centro Universitário Internacional

Prof. Me. André Flávio Gonçalves Silva - Universidade Federal do Maranhão

Prof ${ }^{a}$ Ma. Andréa Cristina Marques de Araújo - Universidade Fernando Pessoa

Prof $^{a}$ Dr $^{\text {a }}$ Andreza Lopes - Instituto de Pesquisa e Desenvolvimento Acadêmico

Prof $^{\text {a }}$ Dr $^{\text {a }}$ Andrezza Miguel da Silva - Faculdade da Amazônia

Prof ${ }^{a}$ Ma. Anelisa Mota Gregoleti - Universidade Estadual de Maringá

Profa Ma. Anne Karynne da Silva Barbosa - Universidade Federal do Maranhão

Prof. Dr. Antonio Hot Pereira de Faria - Polícia Militar de Minas Gerais

Prof. Me. Armando Dias Duarte - Universidade Federal de Pernambuco

Prof ${ }^{a}$ Ma. Bianca Camargo Martins - UniCesumar

Prof $^{a}$ Ma. Carolina Shimomura Nanya - Universidade Federal de São Carlos

Prof. Me. Carlos Antônio dos Santos - Universidade Federal Rural do Rio de Janeiro

Prof. Ma. Cláudia de Araújo Marques - Faculdade de Música do Espírito Santo

Prof ${ }^{\mathrm{a}}$ Dr $^{\mathrm{a}}$ Cláudia Taís Siqueira Cagliari - Centro Universitário Dinâmica das Cataratas

Prof. Me. Clécio Danilo Dias da Silva - Universidade Federal do Rio Grande do Norte

Prof. Me. Daniel da Silva Miranda - Universidade Federal do Pará

Prof $^{a}$ Ma. Daniela da Silva Rodrigues - Universidade de Brasília

Prof ${ }^{a}$ Ma. Daniela Remião de Macedo - Universidade de Lisboa

Prof $^{a}$ Ma. Dayane de Melo Barros - Universidade Federal de Pernambuco

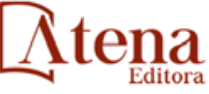


Prof. Me. Douglas Santos Mezacas - Universidade Estadual de Goiás

Prof. Me. Edevaldo de Castro Monteiro - Embrapa Agrobiologia

Prof. Me. Eduardo Gomes de Oliveira - Faculdades Unificadas Doctum de Cataguases

Prof. Me. Eduardo Henrique Ferreira - Faculdade Pitágoras de Londrina

Prof. Dr. Edwaldo Costa - Marinha do Brasil

Prof. Me. Eliel Constantino da Silva - Universidade Estadual Paulista Júlio de Mesquita

Prof. Me. Ernane Rosa Martins - Instituto Federal de Educação, Ciência e Tecnologia de Goiás

Prof. Me. Euvaldo de Sousa Costa Junior - Prefeitura Municipal de São João do Piauí

Prof $^{a}$ Ma. Fabiana Coelho Couto Rocha Corrêa - Centro Universitário Estácio Juiz de Fora

Prof. Me. Felipe da Costa Negrão - Universidade Federal do Amazonas

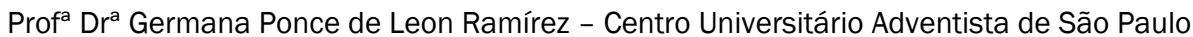

Prof. Me. Gevair Campos - Instituto Mineiro de Agropecuária

Prof. Me. Givanildo de Oliveira Santos - Secretaria da Educação de Goiás

Prof. Dr. Guilherme Renato Gomes - Universidade Norte do ParanáProf. Me. Gustavo Krahl Universidade do Oeste de Santa Catarina

Prof. Me. Helton Rangel Coutinho Junior - Tribunal de Justiça do Estado do Rio de Janeiro

Prof $^{a}$ Ma. Isabelle Cerqueira Sousa - Universidade de Fortaleza

Prof $^{a}$ Ma. Jaqueline Oliveira Rezende - Universidade Federal de Uberlândia

Prof. Me. Javier Antonio Albornoz - University of Miami and Miami Dade College

Prof. Me. Jhonatan da Silva Lima - Universidade Federal do Pará

Prof. Dr. José Carlos da Silva Mendes - Instituto de Psicologia Cognitiva, Desenvolvimento Humano e Social

Prof. Me. Jose Elyton Batista dos Santos - Universidade Federal de Sergipe

Prof. Me. José Luiz Leonardo de Araujo Pimenta - Instituto Nacional de Investigación Agropecuaria Uruguay

Prof. Me. José Messias Ribeiro Júnior - Instituto Federal de Educação Tecnológica de Pernambuco

Prof $^{a}$ Dr $^{a}$ Juliana Santana de Curcio - Universidade Federal de Goiás

Prof ${ }^{a}$ Ma. Juliana Thaisa Rodrigues Pacheco - Universidade Estadual de Ponta Grossa

Prof $^{a}$ Dr $^{a}$ Kamilly Souza do Vale - Núcleo de Pesquisas Fenomenológicas/UFPA

Prof. Dr. Kárpio Márcio de Siqueira - Universidade do Estado da Bahia

Prof ${ }^{a}$ Dr $^{a}$ Karina de Araújo Dias - Prefeitura Municipal de Florianópolis

Prof. Dr. Lázaro Castro Silva Nascimento - Laboratório de Fenomenologia \& Subjetividade/UFPR

Prof. Me. Leonardo Tullio - Universidade Estadual de Ponta Grossa

Prof ${ }^{\mathrm{a}} \mathrm{Ma}$. Lilian Coelho de Freitas - Instituto Federal do Pará

Prof ${ }^{a}$ Ma. Liliani Aparecida Sereno Fontes de Medeiros - Consórcio CEDERJ

Prof $^{a}$ Dra $^{a}$ Lívia do Carmo Silva - Universidade Federal de Goiás

Prof. Dr. Lucio Marques Vieira Souza - Secretaria de Estado da Educação, do Esporte e da Cultura de Sergipe

Prof. Me. Luis Henrique Almeida Castro - Universidade Federal da Grande Dourados

Prof. Dr. Luan Vinicius Bernardelli - Universidade Estadual do Paraná

Prof. Dr. Michel da Costa - Universidade Metropolitana de Santos

Prof. Dr. Marcelo Máximo Purificação - Fundação Integrada Municipal de Ensino Superior

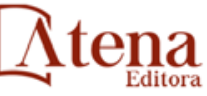


Prof. Me. Marcos Aurelio Alves e Silva - Instituto Federal de Educação, Ciência e Tecnologia de São Paulo

Prof ${ }^{a}$ Ma. Maria Elanny Damasceno Silva - Universidade Federal do Ceará

Prof ${ }^{a}$ Ma. Marileila Marques Toledo - Universidade Federal dos Vales do Jequitinhonha e Mucuri

Prof. Me. Ricardo Sérgio da Silva - Universidade Federal de Pernambuco

Prof $^{a}$ Ma. Renata Luciane Polsaque Young Blood - UniSecal

Prof. Me. Robson Lucas Soares da Silva - Universidade Federal da Paraíba

Prof. Me. Sebastião André Barbosa Junior - Universidade Federal Rural de Pernambuco

Prof $^{a}$ Ma. Silene Ribeiro Miranda Barbosa - Consultoria Brasileira de Ensino, Pesquisa e Extensão

Prof $^{a}$ Ma. Solange Aparecida de Souza Monteiro - Instituto Federal de São Paulo

Prof. Me. Tallys Newton Fernandes de Matos - Faculdade Regional Jaguaribana

Prof $^{a}$ Ma. Thatianny Jasmine Castro Martins de Carvalho - Universidade Federal do Piauí

Prof. Me. Tiago Silvio Dedoné - Colégio ECEL Positivo

Prof. Dr. Welleson Feitosa Gazel - Universidade Paulista 
Editora Chefe: Prof $^{\mathrm{a}} \mathrm{Dr}^{\mathrm{a}}$ Antonella Carvalho de Oliveira

Bibliotecária: Janaina Ramos

Diagramação: Maria Alice Pinheiro

Correção: Kimberlly Elisandra Gonçalves Carneiro

Edição de Arte: Luiza Alves Batista

Revisão: Os Autores

Organizadores: Américo Junior Nunes da Silva Ilvanete dos Santos de Souza

Reinaldo Feio Lima

Dados Internacionais de Catalogação na Publicação (CIP)

E24 Educação e a apropriação e reconstrução do conhecimento científico 4 / Organizadores Américo Junior Nunes da Silva, Ilvanete dos Santos de Souza, Reinaldo Feio Lima. - Ponta Grossa - PR: Atena, 2020.

Formato: PDF

Requisitos de sistema: Adobe Acrobat Reader Modo de acesso: World Wide Web

Inclui bibliografia

ISBN 978-65-5706-604-1

DOI 10.22533/at.ed.990202411

1. Educação. I. Silva, Américo Junior Nunes da (Organizador). II. Souza, Ilvanete dos Santos de (Organizadora). III. Lima, Reinaldo Feio (Organizador). IV. Título.

CDD 370

Elaborado por Bibliotecária Janaina Ramos - CRB-8/9166

Atena Editora

Ponta Grossa - Paraná - Brasil

Telefone: +55 (42) 3323-5493

www.atenaeditora.com.br

contato@atenaeditora.com.br 


\section{DECLARAÇÃO DOS AUTORES}

Os autores desta obra: 1. Atestam não possuir qualquer interesse comercial que constitua um conflito de interesses em relação ao artigo científico publicado; 2. Declaram que participaram ativamente da construção dos respectivos manuscritos, preferencialmente na: a) Concepção do estudo, e/ou aquisição de dados, e/ou análise e interpretação de dados; b) Elaboração do artigo ou revisão com vistas a tornar o material intelectualmente relevante; c) Aprovação final do manuscrito para submissão.; 3. Certificam que os artigos científicos publicados estão completamente isentos de dados e/ou resultados fraudulentos. 


\section{APRESENTAÇÃO}

Esta obra surge no bojo de uma pandemia: a do novo coronavírus. Contexto marcado pelo distanciamento social e consequentemente a suspensão das atividades presenciais em escolas e universidades. Segundo a Organização das Nações Unidas para a Educação, a Ciência e a Cultura (UNESCO), a pandemia da COVID-19 já impactou os estudos de mais de 1,5 bilhão de estudantes em 188 países. E é nessa conjuntura de um "novo normal" que os autores dessa obra organizam as produções que compõem este volume.

Boaventura de Souza Santos ${ }^{1}$ em sua obra "A cruel pedagogia do vírus" nos apresenta algumas reflexões sobre os desafios desse período emergencial e lança luz sobre as desigualdades sociais evidenciadas por esse panorama. E consequentemente, na Educação, esses aspectos compactuam de algum modo, ao acentuar a exclusão daqueles que não conseguem adequar-se desencadeando impactos no ensino como, por exemplo, acesso a tecnologia, reinvenções metodológicas e a mudança de rotina da sala de aula, dentre outros. O cenário emergencial potencializa os desafios e traz à baila as fragilidades do ensino, ainda em fase de apropriação, pois precisam ser compreendidos, ou seja, as informações carregam intencionalidade.

As discussões realizadas neste volume 4 de "Educação e a Apropriação e Reconstrução do Conhecimento Científico", perpassam pela Educação e seus diferentes contextos e reúnem estudos de autores nacionais e internacionais. Este livro, portanto, reúne trabalhos de pesquisa e experiências em diversos espaços, com o intuito de promover um amplo debate acerca das diversas problemáticas que permeiam o contexto educacional brasileiro. Os capítulos que compõe essa obra abordam, de forma interdisciplinar, a partir da realização de pesquisas, relatos de casos e revisões, problemas e situações comuns do contexto educacional.

Por fim, ao levar em consideração todos os elementos que apresentamos anteriormente, esta obra, a partir das discussões que emergem de suas páginas, constituise enquanto importante leitura para aqueles que fazem Educação no país e que se interessam pelas temáticas aqui discutidas. Nesse sentido, desejamos uma boa leitura a todos e a todas.

Américo Junior Nunes da Silva Ilvanete dos Santos de Souza

Reinaldo Feio Lima

1 SANTOS, Boaventura de Sousa. A Cruel Pedagogia do Vírus. Editora Almedina, Portugal. 2020. 


\section{SUMÁRIO}

CAPÍTULO 1

A EDUCAÇÃO A DISTÂNCIA COMO POLÍTICA PÚBLICA DE ACESSO AO ENSINO SUPERIOR

Geanice Raimunda Baia Cruz

Gilmar Pereira da Silva

DOI 10.22533/at.ed.9902024111

CAPÍTULO 2

ENSINAR E APRENDER BIOLOGIA EM PORTUGAL E NO BRASIL - O PAPEL DOS MAPAS DE CONCEITOS

Pedro Yan Ozório de Gouvêa

Mírian Quintão Assis

Pâmella Leite Sousa Assis

André Araújo de Meireles

Abdy Augusto Silva

Isabel Abrantes

Betina Lopes

DOI 10.22533/at.ed.9902024112

CAPÍTULO 3

A COORDENAÇÃO PEDAGÓGICA E A DOCÊNCIA NA ESCOLA DE ENSINO FUNDAMENTAL: ENTRE-LUGARES DA ATUAÇÃO E DA FORMAÇÃO PROFISSIONAL

Giuliana Sampaio de Vasconcelos Coelho

Carla Helena Fernandes

DOI 10.22533/at.ed.9902024113

CAPÍTULO 4

PERMANÊNCIA E ÊXITO E POLÍTICAS PÚBLICAS NA EDUCAÇÃO PROFISSIONAL TECNOLÓGICA: ANÁLISE DO PERFIL SOCIOECONÔMICO DOS DISCENTES DO IFAM, AS AÇÕES DE PERMANÊNCIA E ÊXITO E DEMANDAS PARA A EQUIPE MULTIPROFISSIONAL NO IFAM

Marlene de Deus Lima

Luciana Vieira dos Santos

Sara Carneiro da Silva

DOI 10.22533/at.ed.9902024114

CAPÍTULO 5

CULTURAS ESCOLARES, LIDERANÇAS, PROCESSO DE ENSINO APRENDIZAGEM E RESULTADOS: APRESENTAÇÃO DE DADOS DE UM ESTUDO DE CASO DUPLO COMPARATIVO

Sílvia Maria de Sousa Amorim

Maria llídia de Meireles Cabral da Rocha

José Joaquim Matias Alves

Rosário Serrão Cunha

DOI 10.22533/at.ed.9902024115 
AS ESCOLHAS DOS PROFESSORES COMO EXPRESSÃO DE SEUS SABERES E FAZERES

Telma Alves

DOI 10.22533/at.ed.9902024116

CAPÍTULO 7 70

LÊLÊ GOSTA DO QUE VÊ, E VOCÊ? AS TRAVESSIAS DAS CRIANÇAS NO PERCURSO DA SUA CONSTRUÇÃO IDENTITÁRIA

Rosemary Lapa de Oliveira

Daniela Loureiro Barretto

DOI 10.22533/at.ed.9902024117

CAPÍTULO 8 80

A EXTENSÃO EM ATIVIDADES DE FORMAÇÃO DE PROFESSORES

Andréa Cristina Gomes Monteiro

Dávila Carolina Inácio de Souza

Isisleine Dias Koehler

DOI 10.22533/at.ed.9902024118

CAPÍTULO 9 85

DIFERENÇAS INDIVIDUAIS NO PROCESSO DE APRENDIZAGEM EM SALA DE AULA

Neli Aparecida Gai Pereira

Claudio Luiz Orço

Elizandra lop

DOI 10.22533/at.ed.9902024119

CAPÍTULO 10

ATIVIDADES CIRCENSES E AS RELAÇÕES INTERPESSOAIS NA ESCOLA: PERCEPÇÕES DE ALUNOS E ALUNAS

Mariana Harue Yonamine

Fernanda Rossi

DOI 10.22533/at.ed.99020241110

CAPÍTULO 11 103

A INTERNET E O ENSINO DE QUÍMICA: A PESQUISA E LEITURA DE POESIAS COM ALUNOS DO ENSINO MÉDIO

Éverton da Paz Santos

Givanildo Batista da Silva

Eric Fabiano Sartorato de Oliveira

Samir Apaz Otto Ungria

Vinícius Martins Dias Batista

DOI 10.22533/at.ed.99020241111 
PERFIL E EXPECTATIVAS DOS DISCENTES DO CURSO DE MATEMÁTICA LICENCIATURA DA UFAL - CAMPUS ARAPIRACA

Gilmar dos Santos Batista

Allanny Karla Barbosa Vasconcelos

DOI 10.22533/at.ed.99020241112

CAPÍTULO 13 129

UMA INVESTIGAÇÃO SOBRE AS BRINCADEIRAS QUE OCORREM FORA DO ESPAÇO ESCOLAR

Cristina Aparecida Colasanto

Márcia Cerqueira Zanelli

Paloma de Souza Silva

Talma Gabriela dos Santos

Viviane Santos Oliveira

DOI 10.22533/at.ed.99020241113

CAPÍTULO 14

ARTICULAÇÃO ENTRE SAÚDE E EDUCAÇÃO: A EXPERIÊNCIA BRASILEIRA SOB A ÓTICA DO PROFISSIONAL DE EDUCAÇÃO FÍSICA

Paulo Sergio Cardoso da Silva

Marcelo Braz Vieira

DOI 10.22533/at.ed.99020241114

CAPÍTULO 15 154

A PROFISSÃO DOCENTE: ENTRE HISTÓRIA E MEMÓRIA. UMA PESQUISA EM OURO PRETO DO OESTE (RO)

Ivone Goulart Lopes

Verônica dos Santos Quintana Aquado Peres

Jussara Santos Pimenta

DOI 10.22533/at.ed.99020241115

CAPÍTULO 16 167

AVALIAÇÃO E USABILIDADE DE UM OBJETO DE APRENDIZAGEM CRIADO PARA A OLIMPÍADA PARINTINENSE DE MATEMÁTICA - OPM

Aline Santarém Ramos

Manoel Fernandes Braz Rendeiro

DOI 10.22533/at.ed.99020241116

CAPÍTULO 17 181

RESIDÊNCIA PEDAGÓGICA: REPRESENTAÇÃO SOCIAL DE FORMAÇÃO CONTINUADA

Carolina de Castro Nadaf Leal

Helenice Maia

DOI 10.22533/at.ed.99020241117 
ALFABETIZAÇÃO CIENTÍFICA (AC) EA FORMAÇÃO DE PROFESSORES: MAPEAMENTO DAS TENDÊNCIAS DE PESQUISA

Renata de Macedo Vezzani

Maria Delourdes Maciel

DOI 10.22533/at.ed.99020241118

CAPÍTULO 19 .206

A PERCEPÇÃO SOBRE O DESENVOLVIMENTO RURAL NA REGIÃO SERRANA DO RIO DE JANEIRO: OS DESAFIOS DE UM AMBIENTE EM CONSTANTE CONSTRUÇÃO

Bárbara de Medeiros Marinho

Daniel Nazaré de Souza Madureira

Romaro Antonio Silva

Severina Ramos Telécio de Souza

DOI 10.22533/at.ed.99020241119

CAPÍTULO 20 218

SUGGESTIONS TO IMPLEMENT AND ENHANCE INFORMATION LITERACY PROGRAMS Tulio Barrios Bulling

DOI 10.22533/at.ed.99020241120

SOBRE OS ORGANIZADORES 237

ÍNDICE REMISSIVO 


\section{ENSINAR E APRENDER BIOLOGIA EM PORTUGAL E NO BRASIL - O PAPEL DOS MAPAS DE CONCEITOS}

Data de aceite: 01/11/2020

Data de submissão: 03/09/2020

Pedro Yan Ozório de Gouvêa Universidade Federal do Rio de Janeiro, Instituto de Biologia, Rio de Janeiro, BRASIL

Mírian Quintão Assis Universidade Federal do Rio de Janeiro, Instituto de Biologia, Rio de Janeiro, BRASIL

\section{Pâmella Leite Sousa Assis}

Universidade Federal de Viçosa, Departamento de Biologia Geral, Minas Gerais, BRASIL

\section{André Araújo de Meireles}

Universidade Federal de Viçosa, Departamento de Biologia Geral, Minas Gerais, BRASIL

\section{Abdy Augusto Silva}

Universidade Federal de Viçosa, Departamento de Biologia Geral, Minas Gerais, BRASIL

\section{Isabel Abrantes}

Universidade de Coimbra, Departamento de Ciências da Vida, Universidade de Coimbra., Centro de Ecologia Funcional Coimbra, PORTUGAL https://orcid.org/0000-0002-8761-2151
Universidade de Aveiro, Centro de Investigação Didáctica e Tecnologia Educativa na Formação de Formadores (CIDTFF)

Aveiro, PORTUGAL https://orcid.org/0000-0003-0669-1650

RESUMO: A elaboração de mapas de conceitos tem diversas aplicações no âmbito do ensino de Biologia. Neste estudo, após um breve enquadramento teórico, são apresentados cinco mapas de conceitos: (i) "Evolução biológica" (ii) "Membrana plasmática e obtenção de matéria", (iii) "Universalidade e variabilidade da molécula de DNA", (iv) "Reprodução sexuada" e (v) "Hormonas vegetais". Estes mapas foram elaborados no âmbito da unidade curricular Didática da Biologia II, do Mestrado em Ensino de Biologia e Geologia no $3^{\circ}$ ciclo do Ensino Básico e no Ensino Secundário da Universidade de Coimbra no ano letivo 2018-2019. Ao longo da unidade curricular, os estudantes, oriundos do Brasil no âmbito do Programa de Licenciaturas Internacional (PLI), selecionaram temas do ensino de Biologia, planearam, desenvolveram e construíram os respetivos recursos didáticos, incluindo mapas de conceitos. A realização deste trabalho permitiu estabelecer pontes entre os currículos do ensino de Biologia a nível préuniversitário entre Portugal e o Brasil e aprofundar conhecimentos de modo a constituírem uma base científica sólida e atualizada.

PALAVRAS - CHAVE: Mapa de Conceitos; ensino de Biologia; Formação de Professores; Modelos de Aprendizagem; Programa de 


\section{TEACHING AND LEARNING BIOLOGY IN PORTUGAL AND BRAZIL - THE ROLE} OF CONCEPTUAL MAPS

ABSTRACT: The elaboration of conceptual maps has several applications in the field of Biology teaching. In this study, after a brief theoretical framework, five conceptual maps are presented: (i) "Biological evolution" (ii) "Plasma membrane and obtaining matter", (iii) "Universality and variability of the DNA molecule", (iv ) "Sexual reproduction" and (v) "Plant hormones". These maps were elaborated in the scope of the curricular unit Didactics of Biology II, of the Master Course in Biology and Geology Teaching in the 3rd cycle of Basic and in Secondary Education at the University of Coimbra in the academic year 2018-2019. Throughout the course, students, from Brazil under the International Degree Program (PLI), selected topics in Biology education, planned, developed and built their didactic resources, including conceptual maps. The accomplishment of this work allowed to establish bridges between the curricula of Biology teaching at pre-university level between Portugal and Brazil and to deepen knowledge in order to constitute a solid and updated scientific base

KEYWORDS: Conceptual Maps; Biology teaching; Teacher training; Learning Models; International Degree Program (PLI).

\section{I INTRODUÇÃO}

No ensino das Ciências, e em particular no ensino da Biologia, tem-se recorrido a diversos recursos visuais que auxiliem os estudantes na 'transformação de fragmentos de conhecimento' em 'significados pessoais de conhecimento' (Shambaugh, 1995). Um dos recursos visuais mais amplamente estudados, nomeadamente na área do ensino da Biologia, são os mapas de conceitos (Kinchin, 2000, 2001). Este recurso didático, teoricamente fundamentado na teoria de aprendizagem significativa de David Ausubel, foi desenvolvido por David Novak (Novak \& Gowin, 1984) e consiste, de forma genérica, na identificação de conceitos científicos em 'caixas de texto' e sua ligação através de setas. Cada conceito só pode surgir uma vez no mapa. Por sua vez, cada conceito pode estar ligado a muitos outros conceitos (Novak \& Gowin,1984; Kinchin, 2000). Desta forma, os mapas de conceitos permitem evidenciar entendimentos (pessoais, isto é, de cada indivíduo) da relação entre conceitos científicos por meio de frases de ligação, estruturando-os de forma objetiva e sistematizada. É com base neste pressuposto que os mapas de conceitos têm vindo a ser utilizados com fins didáticos diferenciados, tais como revisão de conteúdos, avaliação das aprendizagens e identificação de conceções alternativas (Kinchin, 2000). Presentemente existem vários modelos para construir mapas de conceitos: aranha, fluxograma, hierárquico, mandala, multidimensional, sistemas e visualização em paisagem (Whiteley, 2005). 


\title{
2 I METODOLOGIA
}

Os mapas de conceitos que se apresentam e descrevem sinteticamente na secção seguinte foram elaborados por cinco estudantes a frequentar a unidade curricular Didática da Biologia II, do Mestrado em Ensino de Biologia e Geologia no $3^{\circ}$ ciclo do Ensino Básico e no Ensino Secundário da Universidade de Coimbra no ano letivo 2018-2019.

No âmbito desta unidade curricular os estudantes:

\begin{abstract}
Analisaram os conteúdos de Biologia que constam do Programa da disciplina de Biologia e Geologia $10^{\circ}$ e $11^{\circ}$ anos do ensino secundário em Portugal (Mendes et al., 2003; Direção Geral da Educação, 2018) e selecionaram uma unidade temática que gostariam de trabalhar em profundidade, designadamente- "Hormonas vegetais", "Membrana plasmática \& obtenção de matéria", "Reprodução sexuada", "Universalidade e variabilidade da molécula de DNA" e "Evolução biológica";
\end{abstract}

Para cada tema selecionado, cada estudante elaborou uma planificação a curto prazo (três aulas) e desenvolveu os respetivos recursos didáticos, incluindo um mapa de conceitos.

Segundo Kinchin (2001), apesar dos benefícios de os mapas de conceitos na aprendizagem dos estudantes estarem amplamente evidenciados, é recorrente encontrar resistência em alguns professores na sua utilização:

Despite numerous research reports indicating the classroom benefits of concept mapping, my own experience indicates to me that biology teachers are not exploiting the benefits of concept mapping within their classrooms (...) This suggests there is a problem with classroom concept mapping that has not been explicitly addressed by the literature. (p. 1257).

No mesmo alinhamento de ideias, Hyerle, 1996 (p. 45) refere: "If the teacher is more interested in "correcting" or editing ideas to fit a lesson, the whole point [of mapping] has been lost."

No sentido de minimizar a problemática identificada pela literatura da especialidade, as docentes da unidade curricular desenvolveram uma sequência didática específica para a exploração dos mapas de conceitos com cinco fases distintas e que se descrevem de seguida.

Fase 1- Apresentação e discussão dos pressupostos teóricos associados à elaboração dos mapas de conceitos em sala de aula de acordo com David Novak e partilha de estratégias diferenciadas de utilização dos mapas de conceitos por professores de Biologia em articulação com pressupostos associados aos modelos de aprendizagem socio-construtivistas (Lopes, 2013). 
Fase 2- Revisão da literatura no âmbito da área de saber específica do tema selecionado (ex. Evolução) e elaboração de uma primeira proposta de listagem de conceitos-chave. Discussão interpares dessa mesma listagem e primeiro ciclo de validação com as docentes da unidade curricular.

Fase 3- Elaboração do primeiro esboço do mapa de conceitos por cada um dos estudantes e sua apresentação oral aos colegas e às duas docentes. Sessão de "brainstorming" para atualização, enriquecimento do mapa de conceitos.

Fase 4- Validação (científica) de cada mapa de conceitos por um especialista da área do saber específico, investigador na Universidade de Coimbra.

Fase 5- Apresentação do mapa de conceitos no final da unidade curricular e sua integração na versão final no relatório escrito.

Por fim, salienta-se que estes mapas de conceitos foram elaborados por estudantes brasileiros do Programa de Licenciaturas Internacionais (PLI) ${ }^{1}$. Assim, a realização deste trabalho permitiu estabelecer pontes com a Base Nacional Comum Curricular (Ministério da Educação, 2017) e aprofundar conhecimentos de modo a constituírem uma base sólida e atualizada dos temas que se lecionam no ensino médio brasileiro, nomeadamente ao nível do $1^{\circ}$ ano (Membrana plasmática e obtenção de matéria), $2^{\circ}$ ano (Reprodução sexuada e Universalidade e variabilidade da molécula de DNA) e $3^{\circ}$ ano (Hormonas vegetais e Evolução biológica).

\section{I RESULTADOS}

Tal como referido anteriormente, os resultados deste estudo correspondem às versões finais dos cinco mapas de conceitos, que se constituem recursos didáticos cientificamente validados e com potencial para serem adaptados por qualquer professor do ensino pré-universitário de Biologia em Portugal e no Brasil, de acordo com os objetivos de aprendizagem pretendidos. Os respetivos mapas de conceitos finais, encontram-se reproduzidos no Anexo (Figs. 1-5).

Segue-se uma breve descrição dos conteúdos nucleares de cada mapa de conceitos, assim como sugestões de leitura e/ou aplicação em estratégias futuras.

- "Evolução biológica" - Este mapa de conceitos explora as principais teorias científicas e hipóteses acerca da Evolução, nomeadamente Lamarckismo (teoria refutada), Fixismo (doutrina filosófica), Geração espontânea (teoria refutada), Criacionismo (hipótese de caráter religioso criacionista) (Andrade \& Barbosa, 2013) e Darwinismo (teoria 10 Programa de Licenciaturas Internacionais (PLI) resultou de uma iniciativa da CAPES e da Universidade de Coimbra, que visa a melhoria do ensino dos cursos de licenciatura e a formação de professores. A partir de 2012, o Programa foi alargado a outras Instituições de Ensino Superior portuguesas. No ano letivo 2016/17 os contornos deste programa foram alterados, uma vez que já não se trata de um programa de dupla titulação, mas sim de um programa de mobilidade académica, reduzindo-se também o período de estudos de dois para um ano letivo. Para mais informação consultar: https://www.uc.pt/pli/sobre 
precursora do Neodarwinismo), Neodarwinismo (teoria aceite atualmente) (Mendes, et al., 2003). O foco neste trabalho foi explorar a diferença entre teoria e hipótese, com os alunos de Biologia, destacando-se a teoria científica que explica um evento de forma sistemática e coerente. Sistemática, porque se baseia num sistema, o método científico, do qual a hipótese é uma parte do método, e coerente porque se baseia em evidências, factos e provas que confirmam a veracidade da teoria. A hipótese pode ser refutada ou aceite no método científico. Para além disso, pretende-se que, com a exploração deste mapa, os alunos passem a ter uma atitude mais crítica.

- "Membrana plasmática e obtenção de matéria" - Este mapa de conceitos sistematiza ideias relacionadas com a temática membrana plasmática e obtenção de matéria pelos seres autotróficos e heterotróficos, tendo como objetivo associar a importância da membrana plasmática para a obtenção de matéria pelos seres heterotróficos. Desta forma, este mapa partiu do princípio de que todos os seres vivos possuem membrana plasmática como envoltório que delimita e mantém a integridade da célula, assegurando a troca de substâncias, de energia e informações entre os meios intra e extracelular (Mendes, et al., 2003). Com isso, pode-se explorar mecanismos de obtenção de matéria dos seres vivos, conhecer a estrutura da membrana plasmática e suas funções, em particular, a troca e transporte de substâncias entre o meio externo e interno das células via transportes mediados e não mediados, passivos, ativos, entre outros (Alberts et al., 2017).

- "Universalidade e variabilidade da molécula de DNA" - Este mapa de conceitos relaciona conceitos da biologia molecular de forma a apresentar as características de hereditariedade, universalidade e variabilidade da molécula de DNA e os processos relacionados a essas características. Um dos pontos chaves desse mapa é a apresentação de Rosalind Franklin pela sua descoberta a cerca da estrutura em dupla hélice do DNA, o que possibilitou um grande salto de conhecimento na história da ciência. Dessa forma, o mapa explora conceitos complexos relacionando-os entre si de forma a possibilitar uma aprendizagem integrada.

- "Reprodução sexuada" - Este mapa de conceitos objetiva analisar três assuntos fundamentais da diversidade de vida num contexto de reprodução sexuada: Meiose, Fecundação e Variabilidade genética. Os dois primeiros são explorados de maneira diferente, enquanto na meiose se explora com um caráter mais molecular e abstrato, na fecundação a abordagem é mais ecológica e concreta, verificando-se que existe uma sinergia dos aspetos moleculares e ambientais que aumentam a variabilidade genética. Essa forma de planear esta temática influenciou a maneira de explorar esse mapa de conceitos. A meiose e a fecundação são facilmente separadas em duas metades, na esquerda e direita respetivamente; sendo ligadas por um quarto assunto que é de muita relevância quando se fala de reprodução sexuada, os gâmetas. A variabilidade genética pode ser percebida em vários contextos e para ajudar sua visualização foi desenvolvido um mecanismo de linhas tracejadas que aponta para a presença da variabilidade. Além 
desse mecanismo, foram desenvolvidos outros (imagens e notas) para ajudar a esclarecer os conceitos. Assim, este mapa de conceitos além de desenvolver aspetos pedagógicos e científicos do professor também contribui para a aprendizagem dos estudantes.

- "Hormonas vegetais" - Este mapa de conceitos. que pode ser usado como apoio à análise e planeamento do currículo, pretende despertar o interesse do aluno, para depois entrar nos detalhes da fisiologia. Apresenta os principais processos que ocorrem nas plantas, através de conceitos e, à medida que se vai desenvolvendo o mapa, o funcionamento desses processos e a relação destes com outros elementos vai sendo mostrada até chegar às hormonas responsáveis por estes. A influência de uma hormona (estímulo e inibição) no funcionamento de outras e de outros processos é também apresentada no mapa. Além disso, optou-se por utilizar um quadro-resumo que mostra o local de produção, por onde é feito o transporte, e dados sobre a descoberta da hormona. No final do mapa há uma imagem esquemática sobre o funcionamento das homonas a nível celular. A estrutura do mapa de conceitos segue o modelo comum utilizado em sala de aula, isto é, parte daquilo que pode ser visto pelas pessoas, para depois entrar nos detalhes moleculares e na dinâmica fisiológica que ocorre na planta. Após a apresentação dos processos, as fitohormonas e os detalhes sobre elas são evidenciados.

\section{4 | CONCLUSÕES}

A elaboração de mapas de conceitos possibilitou ir além do estudo teórico, pois permitiu colocar em prática os conhecimentos pessoais, tendo sido uma etapa fundamental para a formação dos estudantes enquanto futuros professores do ensino pré-universitário. De acordo com as experiências vivenciadas pelos estudantes brasileiros, em Portugal, o mapa de conceitos já é uma realidade enquanto prática na formação de professores, sendo também uma realidade nas salas de aula portuguesas uma vez que é um recurso utilizado em outros cursos de mestrado tal como o Mestrado em Ensino de Geografia no $3^{\circ}$ ciclo do Ensino Básico e no Ensino Secundário da Universidade de Coimbra.

Em síntese, o mapa de conceitos pode ser usado pelo docente na etapa de planeamento e, também, em contexto de sala de aula, na medida em que pode ser construído pelos próprios estudantes, o que permite a otimização do estudo. Trata-se de uma ferramenta fundamental para o ensino de ciências, área disciplinar que tem muitos conceitos e termos específicos. Além disso, e devido ao seu potencial didático, são um meio excelente de comunicação entre professores e estudantes de todas as faixas etárias. Neste sentido convidam-se os leitores deste texto a integrarem estes mapas de conceitos nas suas aulas de Biologia e, caso o desejem, entrar em contacto com os autores deste estudo para partilha de experiências e desenvolvimento de outros recursos didáticos.

No Brasil, o mapa de conceitos é, ainda, pouco utilizado pelos professores e 
estudantes, contudo apresenta-se como um método capaz de ser aplicado no contexto social brasileiro, já que este necessita de alternativas inovadoras e que requerem baixo custo, fugindo do tradicional quadro e giz que permeia a grande maioria das salas no país.

\section{AGRADECIMENTOS}

Os estudantes, e autores deste artigo, Abdy Augusto Silva, André Araújo de Meireles, Mírian Quintão Assis, Pâmella Leite Sousa Assis, Pedro Yan Ozório de Gouvêa manifestam a sua gratidão pela oportunidade que Ihes foi dada através do programa PLI, financiado pela CAPES. Por último, gratificam as Professoras Ginia Bontempo da Universidade Federal de Viçosa, e Maria Teresa Silva Gonçalves do Departamento de Ciências da Vida da Universidade de Coimbra, que deu apoio através de orientação personalizada ao longo desse processo.

As docentes da unidade curricular Didática da Biologia II agradecem aos Colegas, António Moreno, António Portugal, Joana Cardoso, Jorge Canhoto e Rui Ribeiro, a revisão científica dos mapas de conceitos elaborados pelos estudantes.

\section{REFERÊNCIAS}

ALBERTS, Bruce; BRAY, Dennis, HOPKINS, Karen; JOHNSON, Alexander; LEWIS, Julian; RAFF, Martin; ROBERTS, Keith. Fundamentos da Biologia Celular. Porto Alegre: Grupo A Educação, 2017.

ANDRADE, Roney Seixas; BARBOSA, Wilmar do Vale.. Teoria do design inteligente: teoria científica ou discurso religioso? Apontamentos sobre uma controvérsia atual. Horizonte, v.11, p.709-736, 2013.

DIREÇAO GERAL DA EDUCACÃO. Aprendizagens essenciais de Biologia e Geologia $11^{\circ}$ ano ensino secundário. Lisboa: DGE, 2018. Disponível em: http://www.dge.mec.pt/sites/default/files/ Curriculo/Aprendizagens_Essenciais/11_biologia_e_geologia. pdf Acesso em: 10 abr. 2020.

HYERLE, David. Visual tools for constructing knowledge. Alexandria: Association for Supervision and Curriculum Development, 1996.

KINCHIN, lan. Concept mapping in biology. Journal of Biological Education, v.34, n.2, p. 61-68, 2000.

$\mathrm{KINCHIN,} \mathrm{lan.} \mathrm{If} \mathrm{concept} \mathrm{mapping} \mathrm{is} \mathrm{so} \mathrm{helpful} \mathrm{to} \mathrm{learning} \mathrm{biology,} \mathrm{why} \mathrm{aren't} \mathrm{we} \mathrm{all} \mathrm{doing} \mathrm{it?}$ International Journal of Science Education, v.23, n.12, p. 1257-1269, 2001.

LOPES, Betina. Abordagens ao ensino e práticas de questionamento. 2013. Tese (Doutorado em Didática e Desenvolvimento Curricular) - Universidade de Aveiro - Aveiro. Disponível em https://ria. ua.pt/handle/10773/11930?mode=full. Acesso em 10 jul 2020.

MENDES, Alcina; REBELO, Dorinda; PINHEIRO, E.; PERDIGÃO SILVA, Carlos; AMADOR, Filomena; BAPTISTA, José Fernando Pires; CUNHA, Jorge. Programa de Biologia e Geologia $11 .^{\circ}$ ano. Curso Científico e Humanístico de Ciências e Tecnologias. Lisboa: Ministério da Educação, Departamento do Ensino Secundário, 2003 
MINISTÉRIO DA EDUCAÇÃO. Base nacional comum curricular-Educação é a base. 2017.

Disponivel em http://basenacionalcomum.mec.gov.br/images/BNCC_EI_EF_110518_versaofinal_site.

pdf. Acesso em 10 jul 2020.

NOVAK, John; GOWIN, David. Aprender a aprender. 1984 Lisboa: Plátano Edições Técnicas.

SHAMBAUGH, Neal. The cognitive potential of visual constructions. Journal of visual literacy, v.15, p. 7-24, 1995.

WHITLEY, Sean. Memletics ${ }^{\circledR}$ Concept Mapping Course. 2005 Des Plaines, Illinois: Advanogy Publishing.

\section{ANEXO}

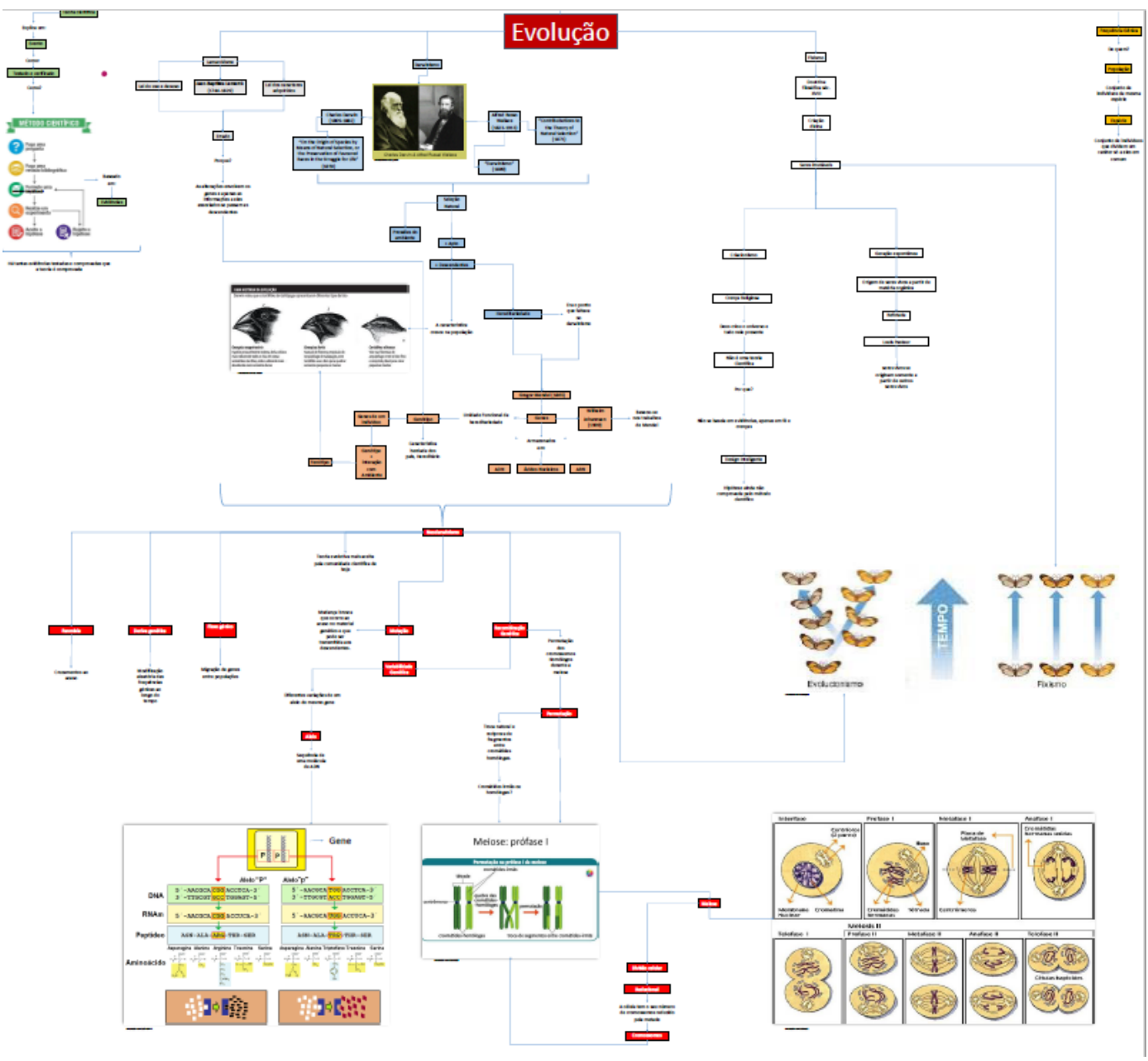

Figura 1. Mapa de conceitos "Evolução biológica” (Pedro Yan Ozório de Gouvêa). 


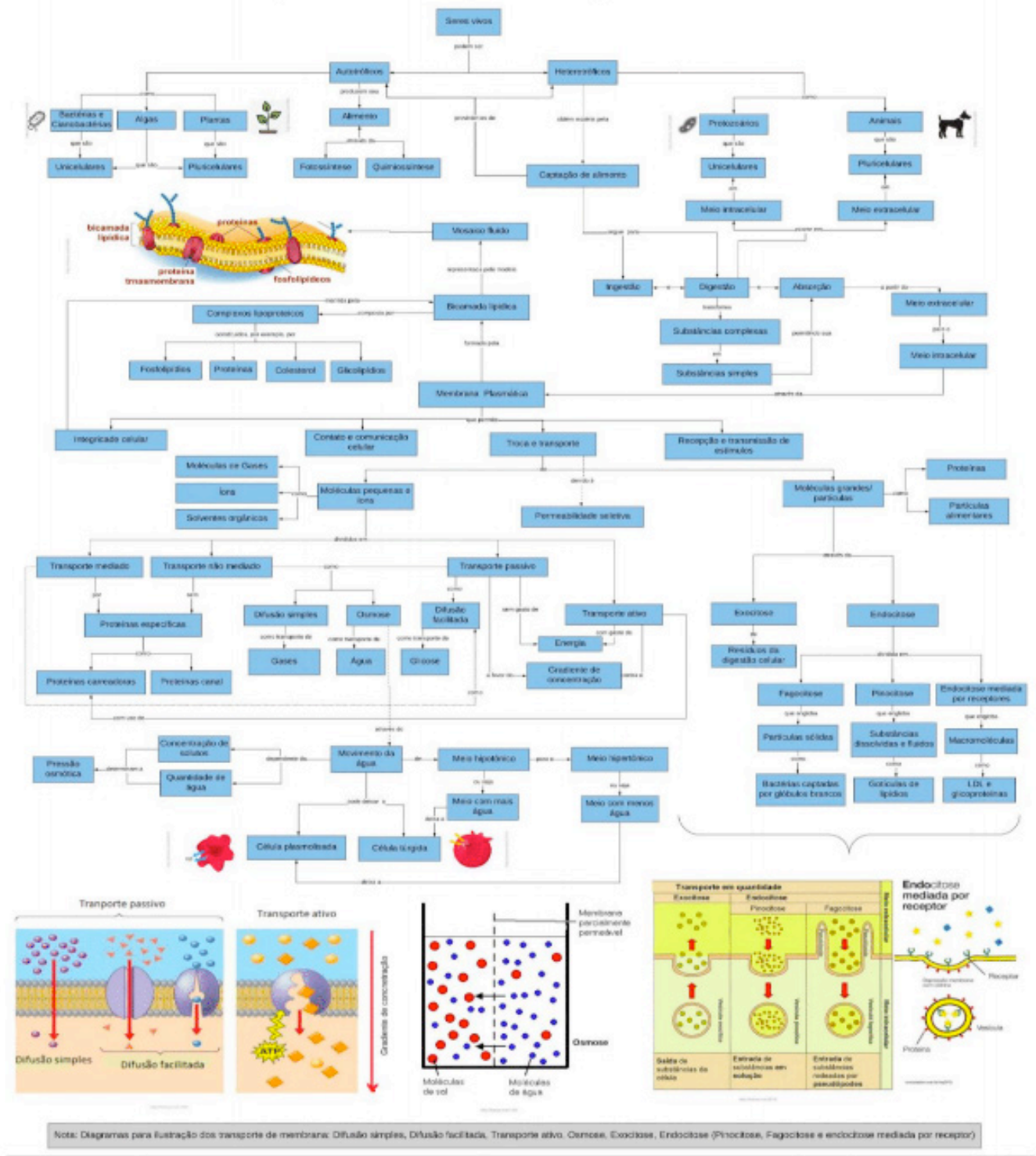

Figura 2. Mapa de conceitos "Membrana plasmática e obtenção de matéria" (Mírian Quintão Assis). 


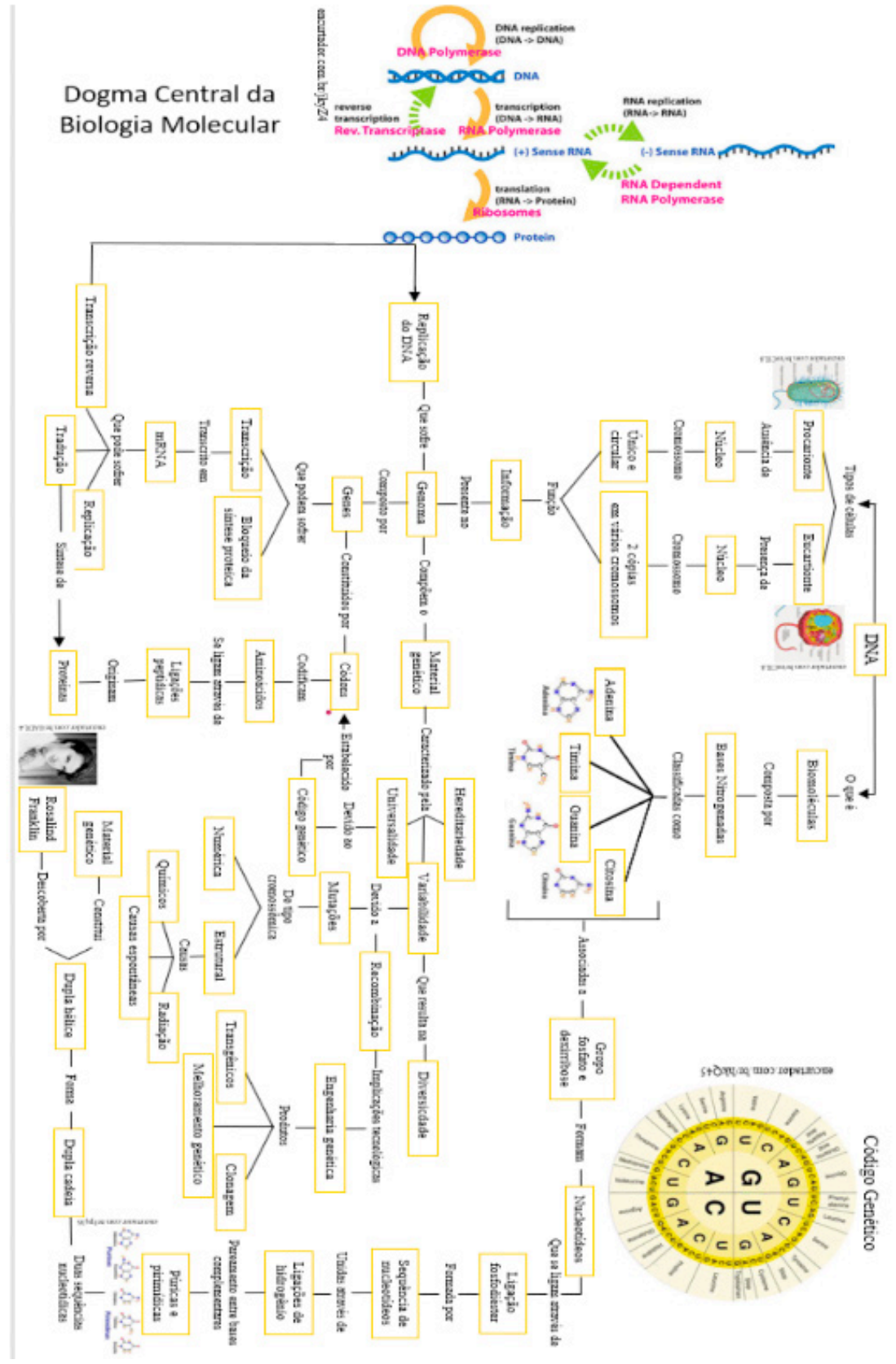

Figura 3 - Mapa de conceitos "Universalidade e variabilidade da molécula de DNA" (Pâmella Leite Sousa Assis). 


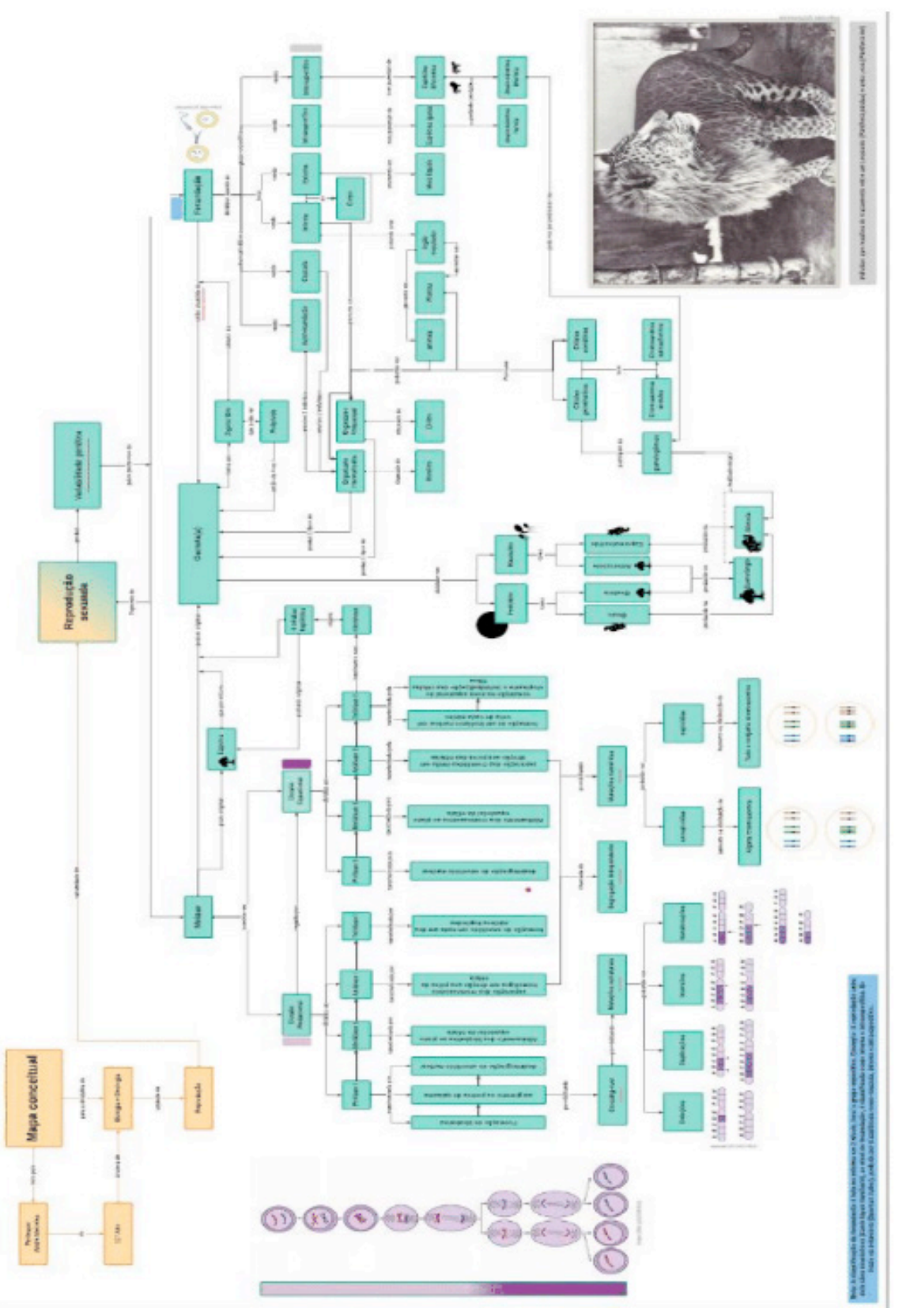

Figura 4. Mapa de conceitos "Reprodução sexuada” (André Araújo de Meireles). 


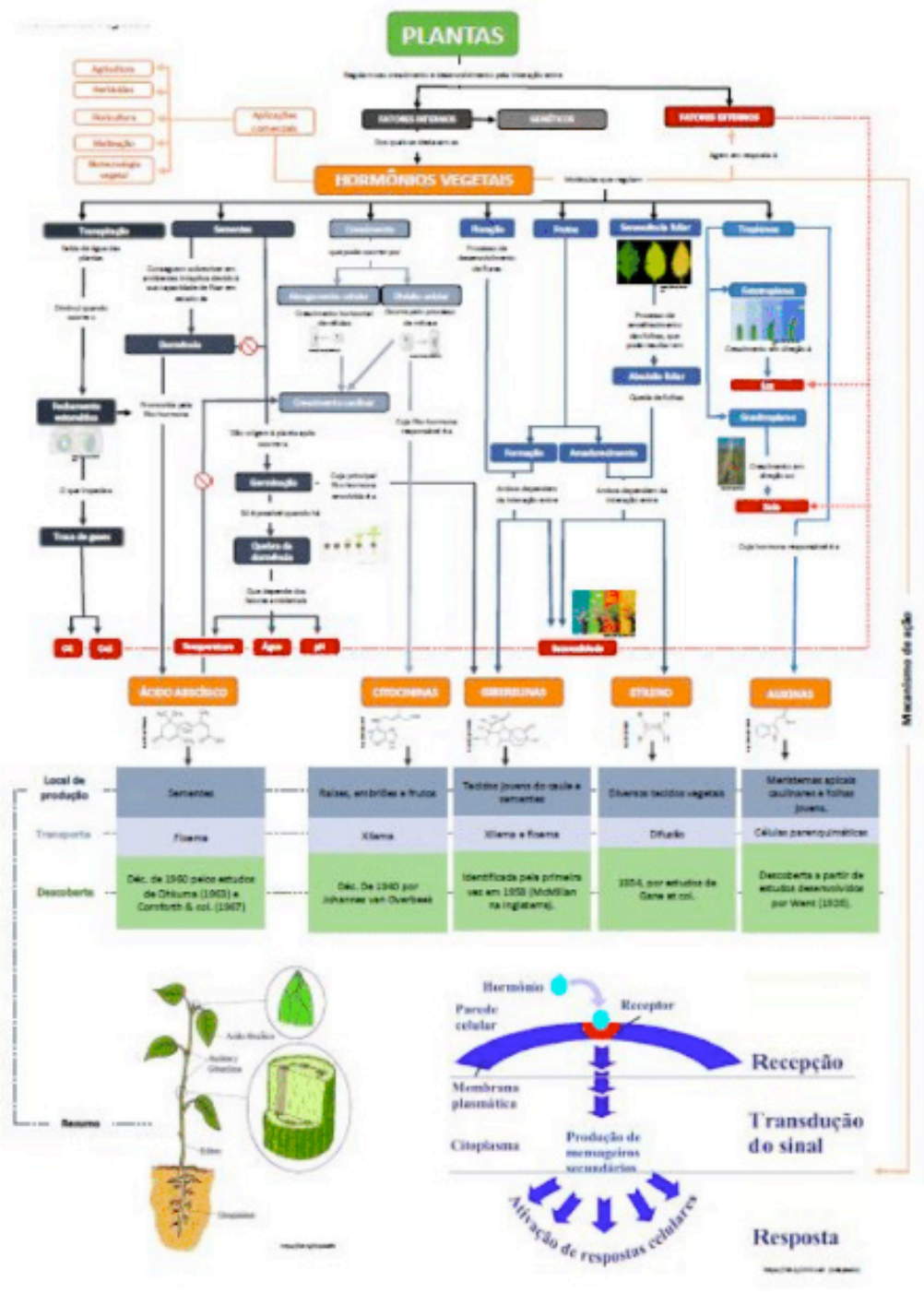

Figura 5 - Mapa de conceitos "Hormonas vegetais" (Abdy Augusto Silva). 


\section{ÍNDICE REMISSIVO}

\section{SÍMBOLOS}

(in)sucesso escolar 49

\section{A}

Agricultura Familiar 206, 213, 217

Alfabetização Científica 13, 192, 193, 195, 196, 197, 201, 202, 203, 204, 205

Alunos 11, 5, 8, 15, 30, 32, 33, 34, 49, 50, 51, 52, 53, 54, 55, 56, 57, 61, 64, 65, 66, 76, 83, $85,86,87,89,93,94,95,96,97,98,100,103,104,106,107,108,109,110,111,112,113$, $115,116,117,118,119,120,121,125,127,128,134,135,158,161,162,163,176,178$, 193, 206, 208, 212, 213, 214, 215, 216

Aprendizagem Matemática 167, 168, 170, 179, 180

Assistência Estudantil 37, 38, 39, 40, 41, 42, 44, 46, 47

Atividades Circenses 11, 93, 94, 95, 96, 97, 98, 99, 100, 101

Avaliação de Software 167, 179

B

Brasil 10, 1, 2, 4, 5, 6, 7, 8, 9, 10, 11, 14, 16, 37, 39, 40, 43, 45, 47, 57, 63, 68, 72, 87, 88, $92,94,97,101,105,107,113,135,139,141,142,143,144,145,146,147,148,149,150$, $151,152,153,155,165,169,184,190,191,193,195,196,202,203,210,212,215,217$

Brincadeiras 12, 71, 94, 96, 97, 129, 130, 131, 132, 133, 134, 135, 136, 137, 138, 139

\section{C}

Coordenação Pedagógica 10, 23, 24, 25, 35, 36

Cultura de escola 49, 56

Curso de extensão 80,83

Curso de matemática 115, 122, 123, 125

D

Desenvolvimento Rural 13, 206, 208, 209, 210, 212, 213, 214, 216, 217

Diferenças Individuais 11, 85, 86, 87, 88, 90, 91

Docência 10, 23, 24, 27, 35, 68, 70, 72, 176, 181, 182, 183, 184, 185, 190, 191, 237

E

Educação 2, 9, 10, 12, 1, 2, 3, 4, 5, 6, 7, 8, 9, 10, 13, 14, 17, 18, 30, 31, 35, 36, 37, 38, 39, $40,41,42,43,45,46,47,48,49,50,52,56,57,58,59,60,61,62,66,67,68,69,70,71$, $72,73,78,79,80,81,82,83,84,85,86,87,88,91,92,93,94,101,102,113,114,117$, $126,127,131,133,136,139,141,142,143,144,145,146,147,148,149,150,151,152$, 
$153,154,155,156,158,159,163,164,165,169,175,176,179,181,182,183,184,185$, 186, 187, 190, 191, 192, 193, 194, 196, 197, 199, 200, 201, 202, 203, 204, 205, 206, 207, 208, 209, 212, 213, 216, 217, 237, 238

Educação à distância 1, 2, 4, 9

Educação Agrícola 206, 207, 208, 212, 216, 217

Educação Física 12, 30, 81, 101, 133, 139, 141, 142, 143, 144, 145, 147, 149, 152, 153

Educação Infantil 31, 70, 71, 72, 73, 78, 79, 136, 139, 169, 184, 200, 202

Educação Tecnológica 37

Ensino de Biologia 11, 13

Ensino de Ciências 16, 169, 179, 192, 193, 194, 202, 203, 204, 205, 216, 237

Ensino de química 11, 103, 113

Ensino Fundamental 10, 23, 24, 31, 39, 93, 95, 113, 163, 181, 183, 184, 185, 190, 196, 197, 202, 203, 204, 205, 213

Ensino Superior 10, 1, 2, 3, 4, 5, 6, 7, 8, 9, 14, 35, 41, 83, 106, 196, 204, 237

Escola 10, 11, 23, 25, 26, 27, 28, 29, 30, 31, 32, 33, 34, 35, 36, 37, 39, 40, 44, 45, 46, 48, $49,50,51,52,53,54,55,56,57,58,64,67,70,73,76,79,85,87,88,89,90,91,92,93$, $94,95,96,97,98,99,100,101,102,103,106,107,113,119,120,129,130,133,134,141$, $142,144,145,146,147,148,149,150,151,152,153,155,156,158,159,161,162,163$, $165,168,171,176,178,182,183,184,188,189,196,213,214$

Estado do Conhecimento 192, 194, 201

Expectativas 12, 115, 116, 128, 178

\section{$\mathbf{F}$}

Formação de Professores 11, 13, 11, 14, 16, 35, 36, 68, 80, 105, 154, 155, 158, 161, 163, 182, 183, 190, 191, 192, 195, 196, 197, 200, 201, 202, 203, 204, 212, 237, 238

Formação Docente 35, 36, 59, 60, 70, 80, 160, 181, 182, 186

Formação Profissional 10, 23, 35, 60, 63, 66, 67, 69, 158

H

História e Memória 12, 154

I

Identidade 28, 32, 33, 54, 62, 68, 70, 72, 74, 75, 77, 78, 79, 97, 106, 138, 155, 158, 161, 164, 165

IFRJ 59, 60, 62, 69

Improvement 218

Infância 70, 71, 72, 99, 100, 129, 130, 132, 136, 138, 140, 151, 166

Information Literacy 13, 218, 219, 223, 225, 226, 227, 229, 230, 235, 236 
Internet 11, 103, 104, 106, 170, 171, 218

$J$

Jogos 30, 71, 94, 96, 97, 129, 130, 132, 133, 135, 136, 137, 138, 139, 171

$\mathbf{L}$

Leitura $9,11,14,71,73,74,103,104,105,106,107,108,109,110,112,113,192,193$, 194, 197, 200

Lideranças $10,49,51,54$

Literatura 1, 3, 13, 14, 70, 78, 86, 95, 166, 218

Lúdico 80, 81, 82, 83, 84, 99

M

Mapa de Conceitos 11, 13, 14, 15, 16

Mapeamento 13, 192, 194, 195, 200

Modelos de Aprendizagem 11, 13

0

Olimpíada Parintinense de Matemática (OPM) 167, 168, 170, 179

Ouro Preto do Oeste/RO 154, 155, 156

$\mathbf{P}$

Pedagogia 9, 35, 47, 62, 63, 67, 68, 81, 82, 83, 88, 92, 101, 113, 129, 130, 135, 139, 154, 158, 163, 213, 214, 237

Perfil 10, 12, 3, 37, 38, 44, 45, 82, 115, 116, 118, 128, 161, 165, 196, 202

Permanência e Êxito 10, 37, 38, 39, 41, 42, 45, 46

Pesquisa 9, 11, 12, 13, 1, 2, 3, 5, 7, 8, 9, 23, 24, 25, 26, 27, 30, 34, 38, 40, 41, 43, 50, 60, $63,68,70,72,73,74,76,77,78,79,81,82,83,84,85,94,95,98,100,101,102,103,104$, $105,106,112,113,115,116,118,121,125,127,128,129,130,134,135,138,139,152$, $154,155,156,163,164,167,168,170,172,173,174,177,179,181,183,186,187,190$, 192, 194, 197, 200, 206, 207, 208, 212, 213, 216, 217, 237, 238

Poesia 103, 106, 107, 109, 110, 111, 112

Políticas Públicas Educacionais 1, 2, 3

Processo Ensino-Aprendizagem 49, 55

Processo Pedagógico 85, 86, 91

PROEJA 42, 43, 59, 60, 62, 63, 66, 67, 68, 69

Programa de Licenciaturas Internacionais (PLI) 11, 14

Programa Saúde na Escola 141, 142, 144, 145, 146, 147, 149, 150, 151, 152, 153

Promoção de Saúde 141, 144, 148, 149, 150 
$\mathbf{R}$

Relações Interpessoais 11, 93, 94, 95, 98, 99, 100, 101

Representações Sociais 181, 185, 188, 189, 190, 191

Residência Pedagógica 12, 181, 184, 185, 186, 189, 191

$\mathrm{S}$

Saberes Docentes 59, 61, 68, 69

Sala de aula $9,11,13,16,26,30,49,50,52,53,54,55,61,69,73,85,86,88,89,90,91$, $92,104,105,106,113,161,166,171,177,189,190,193,201$

Skills Development 218, 229, 230, 231, 232, 233, 234, 235

T

Teoria da argumentação 181 


\section{Educação e a}

Apropriação e

Reconstrução do

\section{Conhecimento}

\section{Científico}
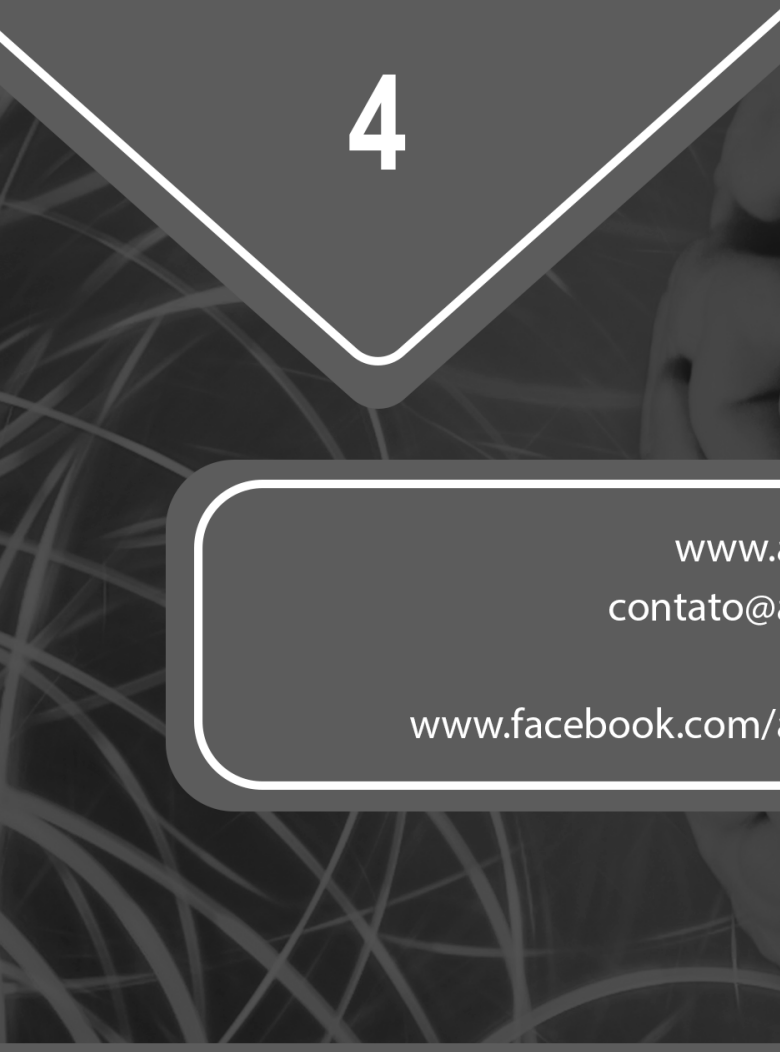

\section{www.atenaeditora.com.br contato@atenaeditora.com.br \ @atenaeditora 우}




\section{Educação e a}

Apropriação e

Reconstrução do

\section{Conhecimento}

\section{Científico}
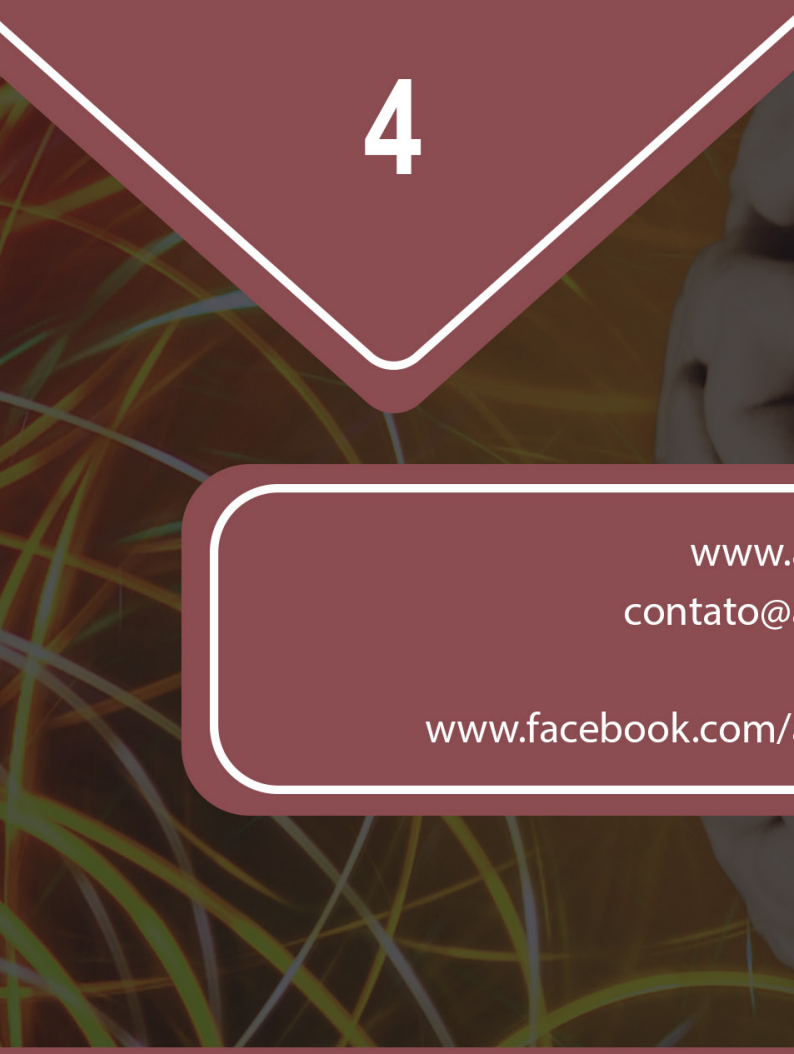

\section{www.atenaeditora.com.br contato@atenaeditora.com.br \4 @atenaeditora 우}

